\title{
Molecular Cloning and Sexually Dimorphic Expression Analysis of nanos2 in the Sea Urchin, Mesocentrotus nudus
}

\author{
Jian Zhang, Xiao Han, Jin Wang, Bing-Zheng Liu, Jin-Liang Wei, Wei-Jie Zhang, Zhi-Hui Sun * \\ and Ya-Qing Chang *
}

Key Laboratory of Mariculture \& Stock Enhancement in North China Sea, Ministry of Agriculture and Rural Affairs, Dalian Ocean University, Dalian 116023, China; zj7782133@163.com (J.Z.); im_hanxiao@163.com (X.H.); wangjin19980318@163.com (J.W.); lbz051014@163.com (B.-Z.L.); m15524575713@163.com (J.-L.W.); zhangweijie@dlou.edu.cn (W.-J.Z.)

* Correspondence: sunzhihui@dlou.edu.cn (Z.-H.S.); yqchang@dlou.edu.cn (Y.-Q.C.); Tel.: +86-411-84762695 (Z.-H.S.); +86-411-84762691 (Y.-Q.C.)

Received: 5 May 2019; Accepted: 30 May 2019; Published: 1 June 2019

\begin{abstract}
Sea urchin (Mesocentrotus nudus) is an economically important mariculture species in China and the gonads are the solely edible parts to human. The molecular mechanisms of gonad development have attracted increasing attention in recent years. Although the nanos 2 gene has been identified as a germ cell marker in several invertebrates, little is known about nanos2 in adult sea urchins. Hereinto, we report the characterization of Mnnano2, an M. nudus nanos2 homology gene. Mnnanos2 is a maternal factor and can be detected continuously during embryogenesis and early ontogeny. Real-time quantitative PCR (RT-qPCR) and section in situ hybridization (ISH) analysis revealed a dynamic and sexually dimorphic expression pattern of Mnnano2 in the gonads. Its expression reached the maximal level at Stage 2 along with the gonad development in both ovary and testis. In the ovary, Mnnanos2 is specifically expressed in germ cells. In contrast, Mnnanos2 is expressed in both nutritive phagocytes (NP) cells and male germ cells in testis. Moreover, knocking down of Mnnanos2 by means of RNA interference (RNAi) reduced nanos2 and boule expression but conversely increased the expression of foxl2. Therefore, our data suggest that Mnnanos 2 may serve as a female germ cell marker during gametogenesis and provide chances to uncover its function in adult sea urchin.
\end{abstract}

Keywords: sea urchins; nanos2; germ cell; RNAi

\section{Introduction}

The Nanos gene encodes an RNA-binding protein and was first identified as a determinant of the anterior-posterior axis in Drosophila melanogaster [1]. Several nanos homologous genes, including Nanos1a, Nanos1b, Nanos2, and Nanos3, have been characterized in diverse species since then [2-6]. Accordingly, their evolutionarily conserved roles in germ cell development have been revealed in both invertebrates [7] and vertebrates [8].

As a member of the Nanos gene family, nanos2 has been identified as a germline stem cells (GSCs) marker that plays an important role in germ cell regeneration [6,9]. However, nanos 2 shows various expression patterns, functions, and regulatory mechanisms among different species. For instance, Nanos2 is predominantly detected in male germ cells in Mammalia (e.g., mouse), and knockout of Nanos2 leads to a complete loss of spermatogonia [8,10,11]. In Aves (e.g., chicken), nanos2 is mainly expressed in testes and promotes the transformation of embryonic stem cells into male germ cells [12]. In contrast, the expression pattern of nanos 2 in fish shows non-uniformly species-specific characteristics. 
For example, nanos2 is expressed in GSCs in zebrafish, but mainly restricted to undifferentiated spermatogonia in rainbow trout $[9,13]$. In Echinodermata, studies of the nanos gene have mainly focused on embryogenesis. For example, nanos is detected primarily in the posterior enterocoel during embryogenesis with a subsequently continuous expression in the germline in sea star (Patiria miniate) and is associated with decreases in the cell cycle of the primordial germ cell (PGC) [14]. In sea urchin (Strongylocentrotus purpuratus), nanos2 is first detected in small micromeres at the 60-cell stage, and it is required for maintaining the small micromere descendants into the larval coelomic pouches $[15,16]$. However, the expression pattern in adult gonads of sea urchin is still unclear.

Mesocentrotus nudus is an echinoid of the Strongylocentrotidae family and is mainly distributed in northern China, the Korean peninsula, the Russian far east coast, and northern Japan [17]. Although the gonads are the only edible part of sea urchins for human, Mesocentrotus nudus is an important mariculture species with high commercial value. Sex differences are one of the most important factors contributing to the quality of sea urchins. For instance, the testis tastes sweet and creamy, whereas the ovaries are bitter and sour [18]. The regulatory mechanisms of gonad development in sea urchins have thus attracted increasing attention in recent years $[19,20]$. However, sea urchins breeding has to suffer long reproductive cycle and low survival rate (range from less than 0.1 to $1 \%$ ) that usually cause intractability. So far, successful gene knockout technology is unavailable to study gene function in adult sea urchin. RNA interference (RNAi), however, provides an alternative approach because of the direct injection of plasmids or RNAs. Moreover, compared to mammals, the effects of RNAi last much longer and it has been used in non-model invertebrate species, such as sea cucumber (Apostichopus japonicus) [21], Zhikong scallop (Chlamys farreri) [22], and Giant Freshwater Prawn (Macrobrachium rosenbergii) [23].

In the present study, we identified the M. nudus nanos 2 gene and characterized its expression patterns during embryogenesis, early ontogeny, and gonad development. Moreover, we investigated its function in gonad development by RNAi, and our data suggest that Mnnanos 2 may play an essential role in germ cell survival in adult sea urchin. This study provides insights into the functional mechanism of nanos 2 in germ cell development and sheds lights on the molecular mechanisms of gametogenesis in sea urchin.

\section{Results}

\subsection{Isolation and Characterization of M. nudus nanos2}

The gonad transcriptome of M. nudus was previously sequenced on the Illumina sequencing platform [19]. To identify the nanos2 gene in M. nudus, we used the evolutionarily conserved RNA-binding zinc finger domain (ZF-domain) amino acid sequence of S. purpuratus NANOS2 (NM_001079555) as the query sequence, and the predicted nanos2 gene (comp145914_c0_seq2) was identified. The nanos 2 cDNA sequence of $M$. nudus (Mnnanos2) was then obtained by $5^{\prime}$ and $3^{\prime}$ RACE. It is 1224-bp in length (MK577422) and contains a 693-bp open reading frame (ORF) that encodes a protein of 230 amino acids, an 84-bp 5'UTR, and a 447-bp 3'UTR. Similar to other species, Mnnanos2 also has a highly conserved ZF-domain (aa 123-176) basing on the result of domain analysis (Figure 1).

Next, we downloaded eight Nanos2 protein sequences from the NCBI database and performed multiple sequence alignment analysis. As shown in Figure 1, the deduced amino acid sequence of $M n$ Nanos2 showed high identity with other echinoderm homologs $(91.7 \%$ with S. purpuratus and $88.9 \%$ with H. pulcherrimus), but low identity with several other non-echinoderm homologs (only $15.2 \%$ with $D$. redio). Furthermore, the ZF-domain of $M n$ Nanos2 exhibited high levels of identity, ranging from $56.6 \%$ to $98.1 \%$, especially with the echinoderms, including the $S$. purpuratus $(98.8 \%)$ and $H$. pulcherrimus ( $98.8 \%$, Figure 2A). Basing upon the multiple protein sequence alignments, a molecular phylogenetic tree was then constructed (Figure 2B). As expected, the phylogenetic tree is divided into distinct echinoderm and chordata clusters, and $M n N a n o s 2$ is grouped with S. purpuratus and H. pulcherrimus Nanos2. Moreover, the topology of clades is basically consistent with the known taxonomic relationships among the species we analyzed. 


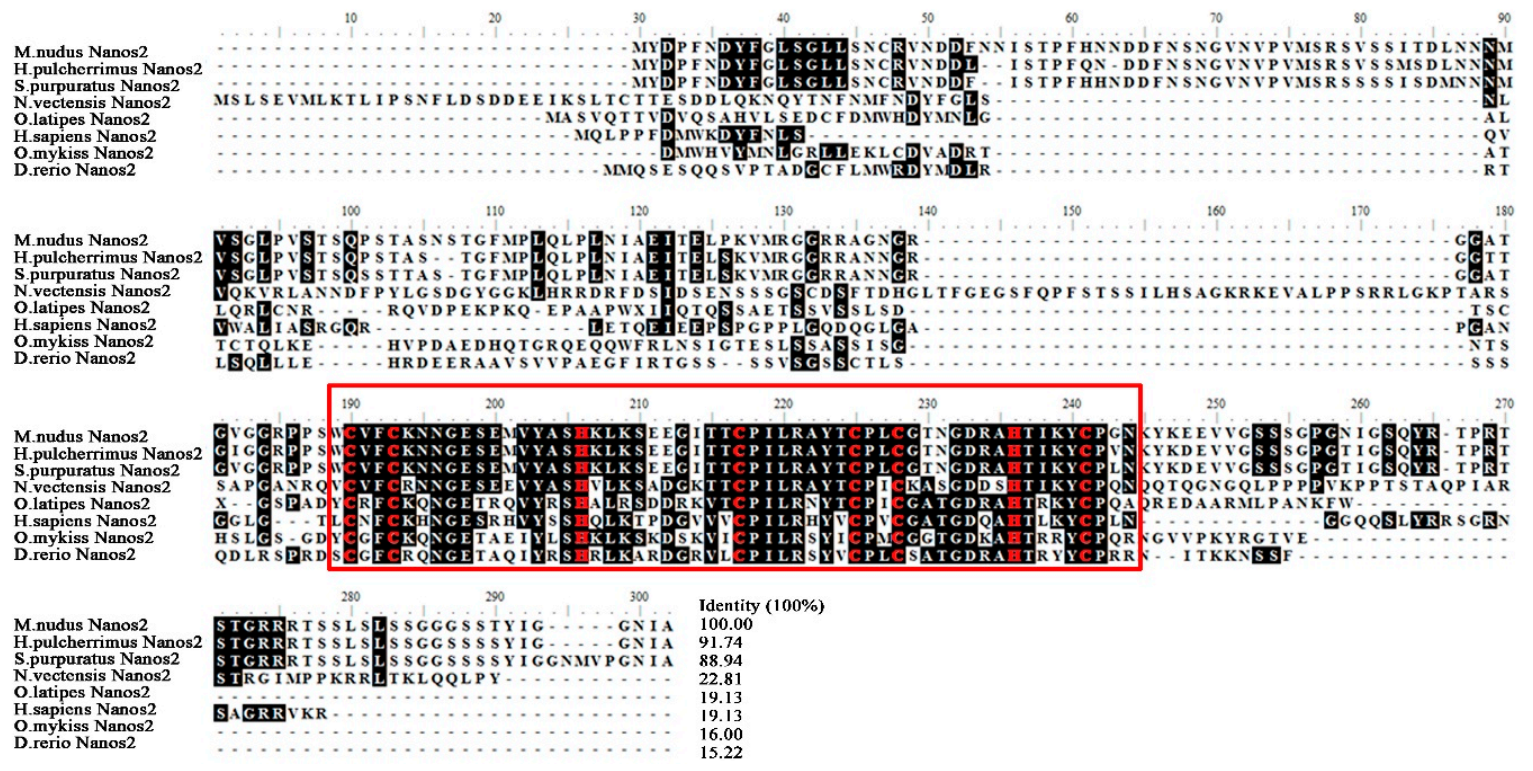

Figure 1. Amino acid alignments of $M n N a n o s 2$ with the homologs from other species. The red box indicate the conserved posotion of zf-domain. The 8 invariant cysteine and histidine residues in zf-domin were marked with red color.

A

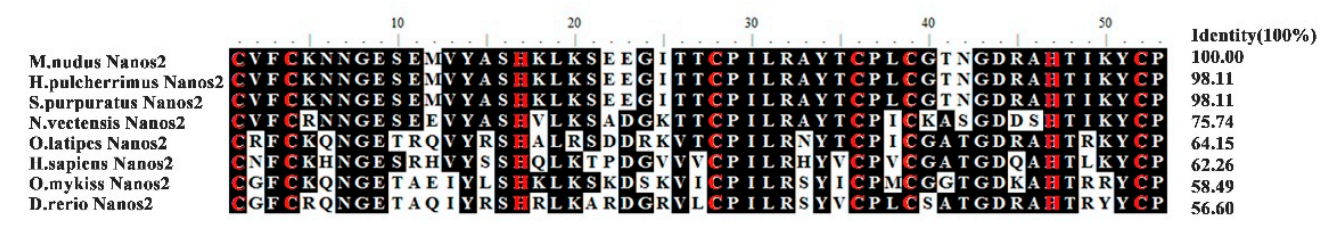

B

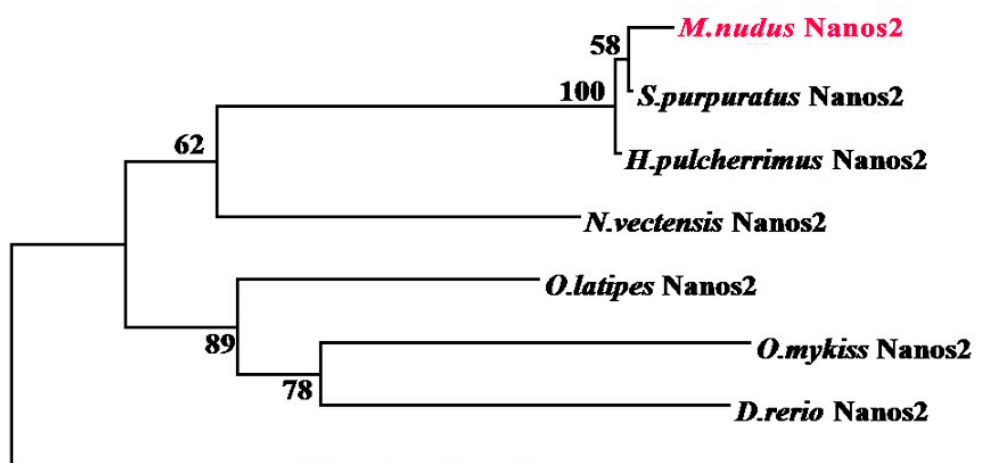

H.sapiens Nanos2

$\mathbf{0 . 1 0}$

Figure 2. Sequence analysis of Nanos2 in M. nudus. (A) Multiple amino acid sequence alignment of Nanos2 ZF-domain, The 8 invariant cysteine and histidine residues in zf-domin were marked with red color. (B) phylogenetic tree of Nanos2.Nanos2 Amino acid of Mesocentrotus nudus was marked with red color. The phylogenetic tree was constructed with MEGA version 5.0 by bootstrap analysis using the maximum-likelihood method (1000 replicates) and human Nanos2 was used as the outgroup sequences. 
2.2. Mnnanos2 mRNA Expression Pattern in Different Adult Tissues and Dynamic Changes during Sex Development

To reveal the expression pattern of Mnnanos2, we measured its mRNA expression by RT-qPCR in different adult tissues, including intestines, tube foot, coelom fluid, ovary, and testis. As shown in Figure 3A, Mnnanos 2 was expressed predominantly in the gonads, which is consistent with its homologs in other species. The ovary and testis of sea urchins are classified into four stages, including inter-gametogenesis and NP phagocytosis (Stage 1), pre-gametogenesis and NP renewal (Stage 2), gametogenesis and NP utilization (Stage 3), the end of gametogenesis, NP exhaustion and spawning (Stage 4) [24]. Hence, we collected the gonads at all four stages during sex development to evaluate the relative expression of Mnnanos2. After histological examination of the gonads (Figure 3C-R), the total RNA of ovary and testis at each stage were isolated for RT-qPCR analysis. In the ovaries, we only detected a small amount of Mnnanos2 transcripts at inter-gametogenesis and NP phagocytosis (Figure 3B). Along with vitellogenic oocytes occurrence, the expression of Mnnanos2 sharply increased up to 81-fold comparing to Stage 1 and reached its peak level at pre-gametogenesis and NP renewal in the ovary. Then, the Mnnanos 2 transcripts were decreased during Stage 3 and Stage 4 (6.4-25-fold lower than Stage 2) as oogenesis progressed. Similar to the ovaries, only a low level of Mnnanos2 transcripts were found at Stage 1 of the testes. At spermatogenesis, the transcriptional levels of Mnnanos2 dramatically increased (about 29-fold comparing to Stage 1) and reached its maximal level at Stage 2, followed by a sharp decrease at Stages 3 and 4 (3.6-5.5-fold lower than Stage 2, Figure 3B).

Next, section tissue in situ hybridization analysis was performed to reveal the Mnnanos 2 cellular localization during gonad development. At Stage 1 of the ovary, Mnnanos 2 was found only in primary oocytes. During ovary development, the Mnnanos 2 transcript was continuously specifically expressed in oocytes (Figure 4A-D). At Stages 1 and 2 of the testes, Mnnanos 2 transcripts were found in all types of the gonad cells, including the germ cells and nutritive phagocytes. However, along with the testis development at Stages 3 and 4, the signals of Mnnanos 2 transcripts were most intense in NP and no positive Mnnanos 2 male germ cells were observed (Figure $4 \mathrm{H}-\mathrm{I}$ ). As expected, we found no positive signals in the hybridization experiments with sense probes (Figure 4E,J). 

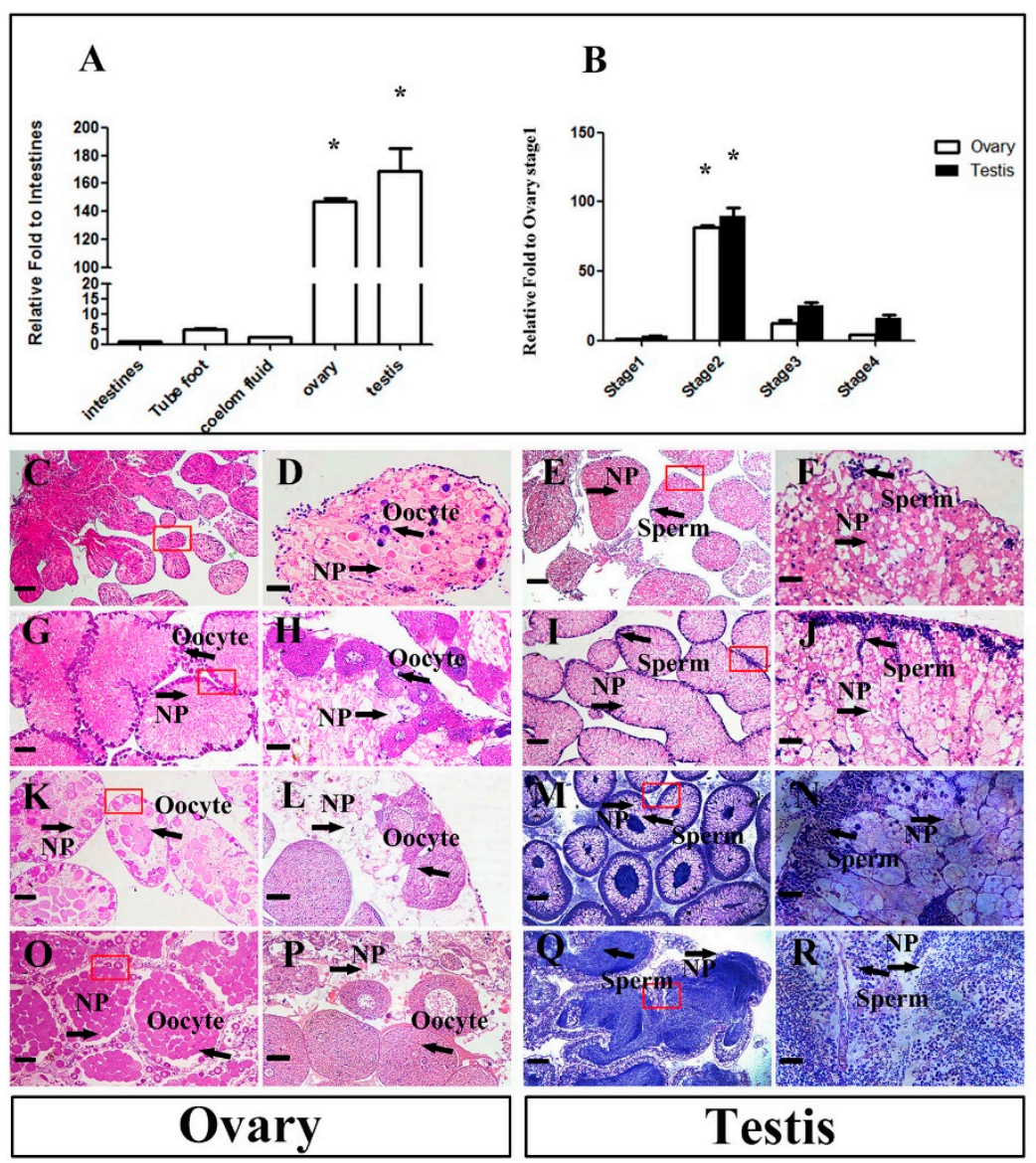

Figure 3. Mnnanos2 expression in adult tissues and gonadal development stages. (A) RT-qPCR analysis of nanos2 expression in different adult tissues. Ubiquitin was used as the control. The expression of Mnnanos 2 in Intestines was set to 1 . Each bar represents mean \pm standard deviation (SD) from three to five individuals. Tukey's test was used to determine statistical analysis. Asterisks $\left(^{*}\right)$ indicate significant differences $(p \leq 0.05)$ between other tissues and intestines. (B) RT-qPCR analysis of nanos2 expression at different gonadal development stages. Ubiquitin was used as the control. The expression of Mnnanos2 at Stage 1 was set to 1 . Each bar represents mean \pm SD from three individuals. Data are from three independent experiments. Asterisks $\left.{ }^{*}\right)$ indicate significant differences $(p \leq 0.05)$ between Stage 2-4 and Stage 1 determined by Tukey's test. $(\mathbf{C}, \mathbf{G}, \mathbf{K}, \mathbf{O})$ Histological detection of the ovary at Stage 1-4. (E,I,M,Q) Histological detection of testis at Stage 1-4. The red boxed areas on the left are shown on the right at higher magnification $(\mathbf{D}, \mathbf{H}, \mathbf{L}, \mathbf{P}, \mathbf{F}, \mathbf{J}, \mathbf{N}, \mathbf{R})$. NP: nutritive phagocytes. Bar: $(\mathbf{C}, \mathbf{G}, \mathbf{K}, \mathbf{O}, \mathbf{E}, \mathbf{I}, \mathbf{M}, \mathbf{Q})$ $200 \mu \mathrm{m}$, and $(\mathbf{D}, \mathbf{H}, \mathbf{L}, \mathbf{P}, \mathbf{F}, \mathbf{J}, \mathbf{N}, \mathbf{R}) 25 \mu \mathrm{m}$. 


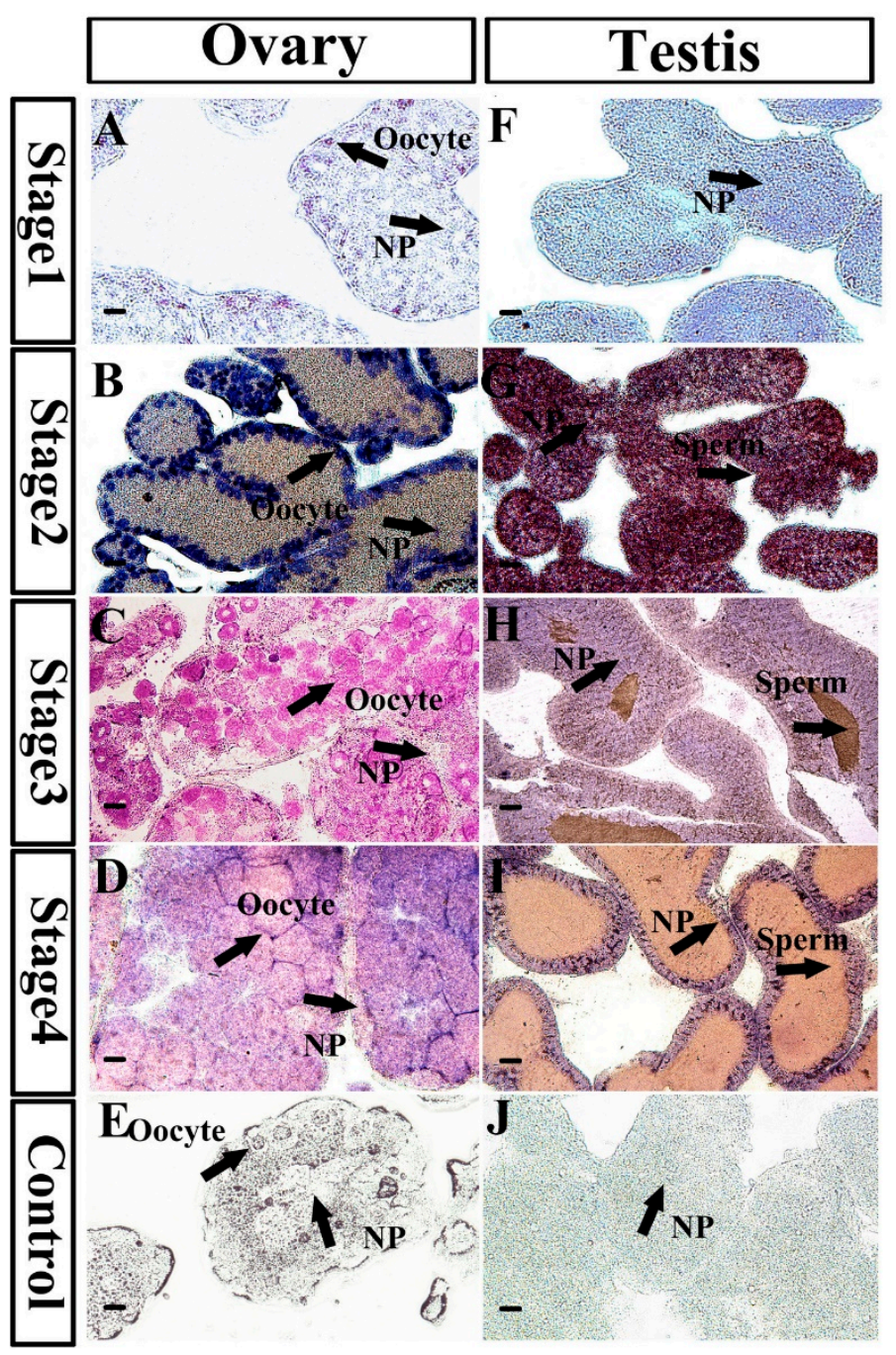

Figure 4. Mnnanos2 expression analysis by in situ hybridization in gonads at different gonadal development stages. (A-E) ovary, (F-J) testis. NP: nutritive phagocytes. Bar $=100 \mu \mathrm{m}$.

\subsection{Mnnanos2 mRNA Expression Pattern during Embryogenesis and Early Ontogeny}

Since abundant Mnnanos2 transcripts were detected in the oocytes, we further detected the expression patterns of Mnnanos2 during embryogenesis and early ontogeny by RT-qPCR. Consistent with previous results in S. purpuratus [16], Mnnanos2 transcripts were detected at early stages from the egg to 16 cells (Figure 5A). At blastula, the expression level of MnNanos2 was significant increased and continuously expressed during prism larva, four carpal and eight carpals (Figure 5A). With ontogenesis, the transcripts of Mnnanos2 could still be detected at three months post-fertilization (mpf), when the shell diameter of $M$. nudus is about $8 \pm 2 \mathrm{~mm}$ (Figure 5B). The expression level of Mnnanos2 decreased subsequently at $6 \mathrm{mpf}$ (shell diameter: $10 \pm 2 \mathrm{~mm}, 1.45$-fold comparing to $3 \mathrm{mpf}$ ), but then sharply increased at 9 and $12 \mathrm{mpf}$ (shell diameters: $13 \pm 2 \mathrm{~mm}$ and $14 \pm 2 \mathrm{~mm}$, respectivley, $>1.9$-fold comparing to $3 \mathrm{mpf}$ ). 
A

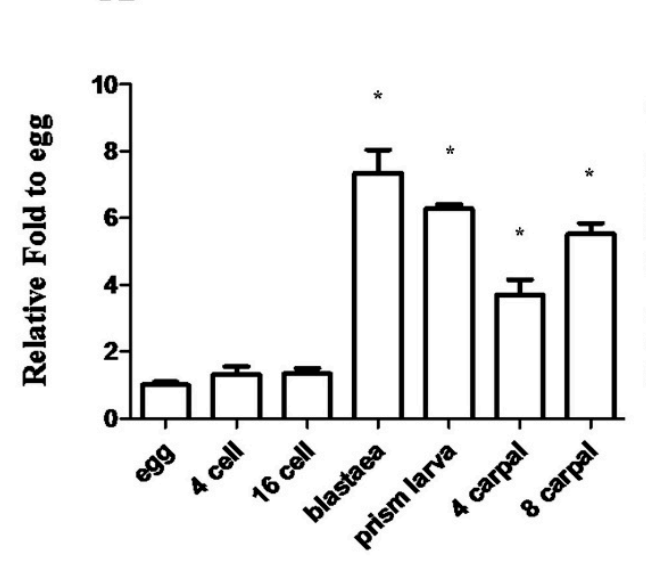

B

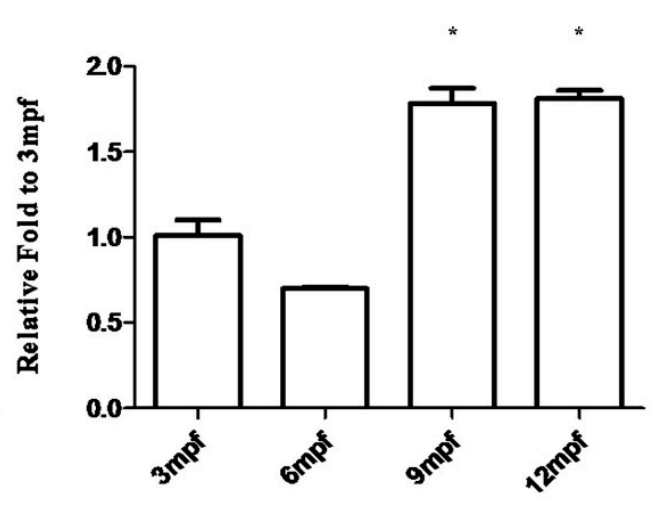

Figure 5. Expression analysis of Mnnanos2 in embryogenesis and early ontogeny. (A) RT-qPCR analysis of nanos2 expression in M. nudus embryos. Ubiquitin was used as the control. The expression of Mnnanos2 in Egg was set to 1. Each bar represents mean \pm standard deviation (SD) from more than 50 individuals. Asterisks $(*)$ indicate significant differences $(p \leq 0.05)$ between 4 cell -8 carpal and egg (B) RT-qPCR analysis of nanos2 expression in early ontogeny of $M$. nudus. Ubiquitin was used as the control. The expression of Mnnanos 2 in $3 \mathrm{mpf}$ was set to 1 . Each bar represents mean $\pm \mathrm{SD}$ from three individuals. Data are from three independent experiments. Asterisks $\left(^{*}\right)$ indicate significant differences $(p \leq 0.05)$ between $6-12 \mathrm{mpf}$ and $3 \mathrm{mpf}$. Mpf: months post-fertilization. Tukey's test was used to determine statistical analysis.

\subsection{Characterization of MnNanos2 Protein Expression Pattern in Gonads}

To further describe the protein expression and cellular localization of $M n$ Nanos2 in gonads, we prepared the anti- $M n$ Nanos2 polyclonal antibody in vitro and performed Western blot detection. We examined the antibody specificity by comparing the pre-immune serum with a pre-adsorbed anti-MnNanos 2 polyclonal antibody. Then, we measured its protein expression by western blotting in different adult tissues, including intestines, tube foot, coelom fluid, ovary, and testis. As shown in Figure $6 \mathrm{~A}$, the anti- $M n$ Nanos2 polyclonal antibody specifically recognized a polypeptide at around $28 \mathrm{kDa}$ (the predicted molecular weight of MnNanos2 is $25.41 \mathrm{kDa}$ ) in both the ovary and testis extracts. Blotting with pre-immuned serum (serum incubated with $M n N a n o s 2$ protein prior to immunoblotting) led to a complete disappearance of this $28 \mathrm{kDa}$ band (Figure 6B). Likewise, when the anti-MnNanos2 polyclonal antibody was pre-adsorbed with the purified recombinant $M n$ Nanos 2 protein at $4{ }^{\circ} \mathrm{C}$ for $16 \mathrm{~h}$, the specific 28 -kDa polypeptide could not be detected by the pre-adsorbed antibody (Figure 6C). Meanwhile, GAPDH was used as the control (Figure 6D) and the full uncut labeled blots can be found in Figure S1. These data indicate that the anti-MnNanos2 polyclonal antibody is specifically expressed in gonads. Furthermore, immunohistochemistry analysis was performed to confirm the cellular localization of $M n$ Nanos2 proteins. Consistent with the ISH results, $M n$ Nanos2 protein was detected in oocytes throughout the development of the ovary (Figure 6E-G). As expected, we found no positive signals in the ovary that were incubated with pre-immuned serum (Figure $6 \mathrm{H}$ ). However, we could not detect the positive signals in testis, Stage 1 ovary (data not shown) and intestines (Figure S2). According to previous studies, many factors including tissue, duration, and type of antigen retrieval can affect the result [25]. 

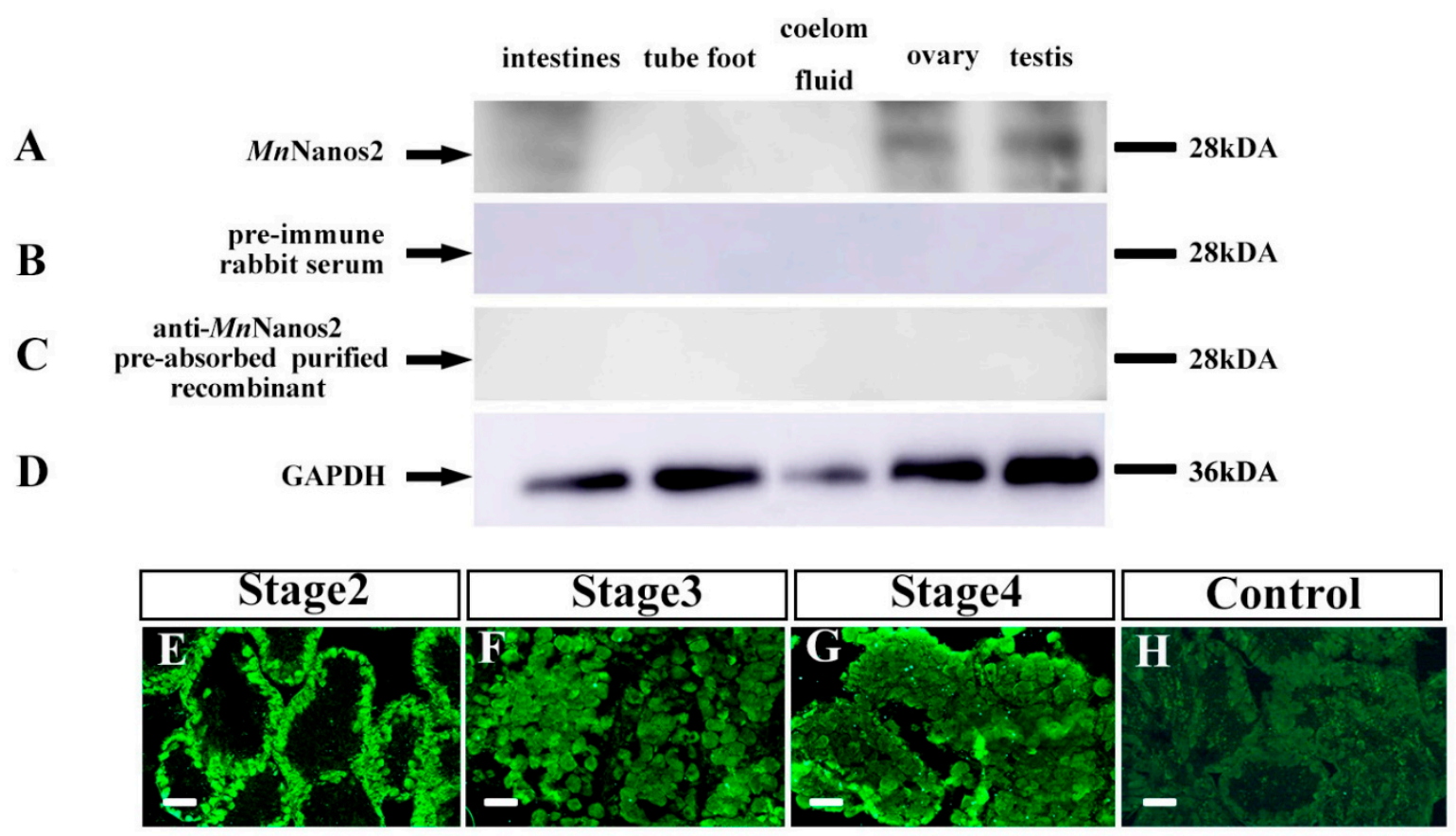

Figure 6. Detection of anti- $M n N a n o s 2$ antibody and immunofluorescence localization of $M n$ Naons 2 in the ovary. (A) Western blot with the anti-MnNanos2 polyclonal antibody in ovary and testis extracts, (B) Western blot with the pre-immune rabbit serum in ovary and testis extracts, (C) Western blot with the anti- $M n$ Nanos2 antibody that had been pre-absorbed with the purified recombinant $M n N a n o s 2$ protein in ovary and testis extracts, (D) GAPDH was used as the control, (E-G) immunofluorescence localization of $M n$ Nanos2 in the ovary, $(\mathbf{H})$ immunofluorescence localization of pre-immuned serum in the ovary. Bar $=100 \mu \mathrm{m}$.

Considering that Nanos2 plays a conserved role in germ cell development [6] and that the MnNanos2 gene is expressed predominantly in gonads, we utilized RNAi to investigate MnNanos2 function in gonad development. Adult $M$. nudus were injected with either specific MnNanos2-targeting double-stranded RNA (dsRNA) or phosphate buffer saline (PBS), and were then divided into the knockdown and control subgroups, respectively. Then we collected gonadal samples at 24 and $72 \mathrm{~h}$ after injection to measure the expression of Mnnanos 2 and other well-studied sex-related genes, including boule [26] and foxl2 [27], by RT-qPCR. As shown in Figure 7A, the expression of boule in the ovary significantly decreased in Mnnanos2-knockdown samples comparing to the control groups at $24 \mathrm{~h}$ after injection. However, the transcripts of Mnnanos 2 and foxl 2 showed quantitatively small differences at the same time point. At $72 \mathrm{~h}$ post injection, the expression of Mnnanos2 and boule significantly decreased by $59.6 \%$ and $56.0 \%$ in the Mnnanos 2 -knockdown group comparing to the control group. Interestingly, the foxl 2 expression level increased about 1.3-fold in the ovary of the knockdown group at $72 \mathrm{~h}$ post injection. In the testes, Mnnanos 2 and boule expression were decreased by $44.0 \%$ and $55.9 \%$ at $24 \mathrm{~h}$ after injection in knockdown adults, respectively. The transcripts of Mnnanos2 and boule were similarly suppressed significantly (by $53.4 \%$ and $58.7 \%$, respectively) in male knockdown adults at $72 \mathrm{~h}$ after injection. In addition, the fox 12 expression in male $M n N a n o s 2-k n o c k d o w n$ adults phenocopied that of the ovaries at $72 \mathrm{~h}$ after injection (Figure $7 \mathrm{~B}$ ). 
A

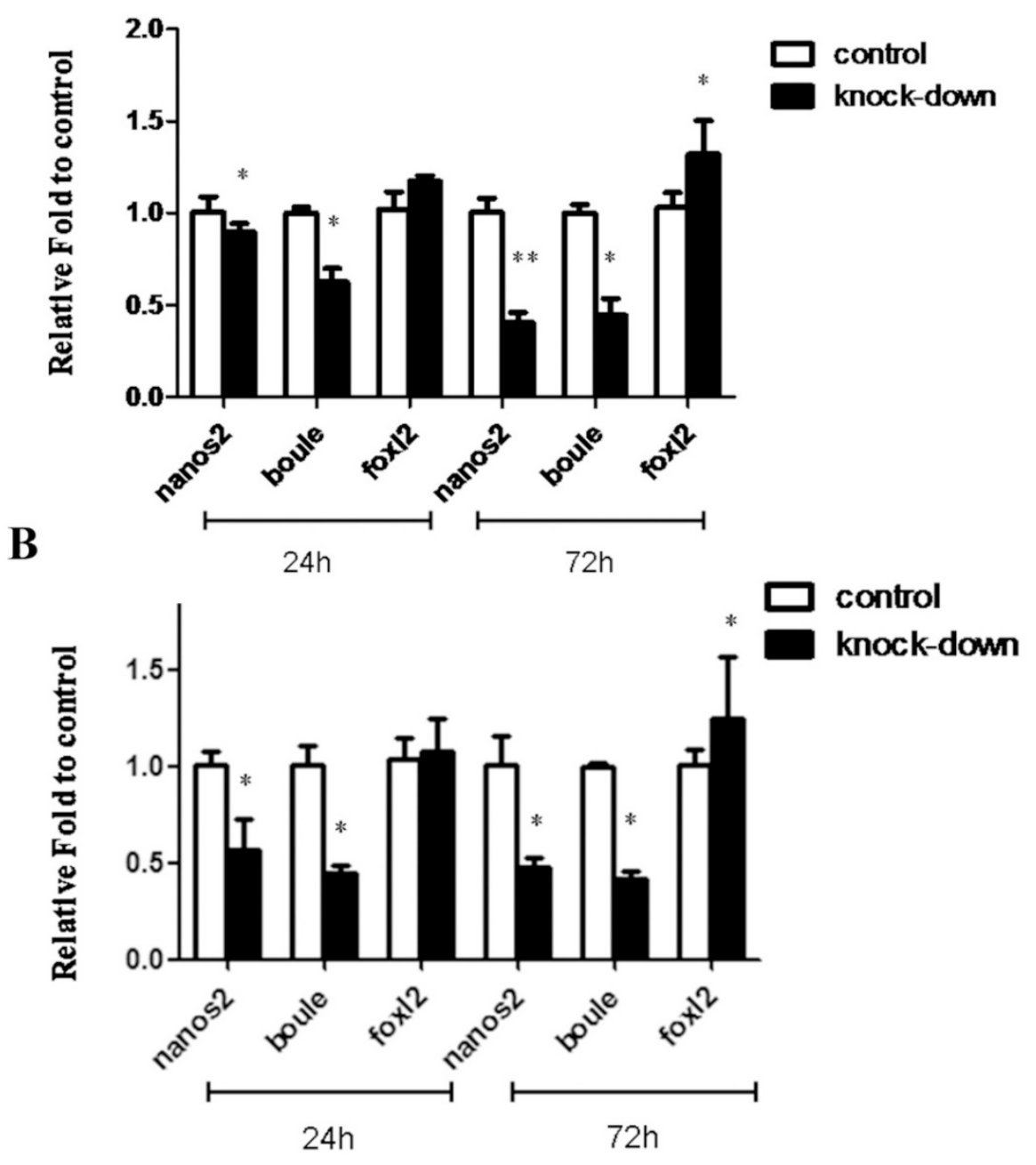

Figure 7. RNA interference (RNAi) of Mnnanos2. RT-qPCR measured the mRNA levels of Mnnanos2 and other sex-related genes after Mnnanos2 RNAi. (A) ovary and (B) testis. Ubiquitin was used as the control. The expression of Mnnanos 2 in control group was set to 1 . Each bar represents mean \pm standard deviation (SD) from three individuals. Asterisks $\left({ }^{*}\right)$ indicate significant differences $(p \leq 0.05)$ between knockdown and control. The datasets were normal distribution by Shapiro-Wilk test. Student's test was used for statistical analysis.

\section{Discussion}

As the only edible part of $M$. nudus, the gonads have dual functions of reproduction and nutrient storage [17]. Therefore, understanding the regulatory mechanisms of gonad development is of great theoretical and practical significance. In this study, we identified the nanos2 gene homolog in $M$. nudus and revealed its molecular characterization, phylogenetic relationships, and sexually dimorphic expression. Importantly, we studied the nanos2 gene function in adult sea urchins with RNAi.

We detected Mnnanos2 in different stages of gonads. Interestingly, the expression level of Mnnanos2 reached its peak at Stage 2 in both the ovary and testis (Figure 3B). This highest mRNA expression at Stage 2 of ovary and testis might be involved in gametogenesis because a large number of oocytes and spermatogenic cells must be produced at the pre-gametogenesis and NP renewal stage. Furthermore, Mnnanos 2 was expressed continuously and specifically in oocytes of the ovary at different stages, and Mnnanos 2 could thus be a marker of oocytes in sea urchins (Figure 4A-D). The specific expression of Mnnanos2 in oocytes indicates that it plays an essential role in regulating oocyte production. However, this expression pattern is different from previous reports about nanos 2 in 
vertebrates. For example, nanos2 is specifically detected in germ stem cells of the ovary in zebrafish [9], medaka [28], and orange spotted grouper [5]. Interestingly, Mnnanos2 was expressed in both the male germ cell and NP cells at Stage 2 of the testis (Figure 4G) and was continuously presented in NP cells during the gonad Stages 3 and 4 (Figure $4 \mathrm{H}-\mathrm{I}$ ). However, this expression pattern is remarkably different from other species. For instance, in inchoate buffalo and trout, the highest nanos 2 mRNA expression is detected in testes and is mainly expressed in undifferentiated type A spermatogonia, thus it should be a molecular marker of spermatogonia $[4,13,29]$. Moreover, Mnnanos 2 was found in embryos, which is similar to Caenorhabditis elegans [30,31], Strongylocentrotus purpuratus [15], and mouse [8,32], but different from most teleost species, in which no nanos 2 mRNA was observed during embryogenesis $[9,19,28]$. This differential pattern of expression may indicate that the gene has gone through functional divergence during millions of years of evolution.

Recently, knock-off [33] and knockdown [34] technologies have been used in sea urchins, but all of these studies have focused on embryonic development. Here, we tried to uncover the function of nanos 2 gene in adult gonads by means of RNAi. By injecting sea urchin with nanos2 dsRNA, we successfully reduced the expression of not just our target gene, but also other conserved germ cell marker genes like boule (Figure 7). In vertebrates as well as invertebrates, nanos 2 and boule have been identified as germ cell markers and play important roles in germ cell development [12,35]. The decreased expression of germ cell marker genes (nanos2 and boule) indicated that the number of germ cells may have decreased, and that Mnnanos2 is essential for germ cell survival in adult sea urchin. Interestingly, the expression level of foxl2 was increased slightly, rather than decreased, in the knockdown ovary and testis comparing to that of the control group. In most species, foxl2 is predominantly expressed in ovarian granulosa cells and is required for ovary differentiation and maintenance [36-40]. Recently, it has been reported that the foxl2 transcript is expressed in both the ovary and testis of M. nudus [19]. However, the mechanism of this increased expression of foxl2 in nanos2-knockdown sea urchins is unclear and should be further studied. These above data suggest that dsRNA injection is an effective method to study gene function in adult sea urchins and that more functional studies need to be carried out on these genes to determine their molecular mechanisms in sea urchin sex development.

In conclusion, we identified the nanos 2 gene homolog in M. nudus and show that Mnnanos 2 is a maternal factor that can be detected continuously during embryogenesis and early ontogeny. Mnnanos 2 displays sexually dimorphic characteristic in gametogenesis, and it might be a germ-cell-specific marker in the ovary. In testis, Mnnanos 2 is expressed both in NP cells and male germ cells, which is different from other species. In addition, the expression level of nanos 2 and boule were significantly decreased while foxl 2 was increased in nanos 2 knockdown sea urchins by RNAi. In the future, the molecular mechanism of nanos 2 in regulating germ cell development should be further investigated in sea urchins.

\section{Materials and Methods}

\subsection{Experimental Animals}

M. nudus used in the experiment were collected from the coastal areas of Dalian, China (38.8073 N, 121.4045 E). The samples of early embryogenesis were obtained from Key Laboratory of Mariculture \& Stock Enhancement in North China Sea, Ministry of Agriculture and Rural Affairs. This study did not involve any endangered or protected species.

\subsection{Gonadal Histology}

Gonadal tissues were surgically removed and fixed in $4 \%$ paraformaldehyde (PFA) at $4{ }^{\circ} \mathrm{C}$ overnight and embedded in Optimal Cutting Temperature (O.C.T). at room temperature. Then, sections $(3 \mu \mathrm{m})$ were cut and stained with hematoxylin/eosin (HE; Beyotime Institute of Biology, Suzhou, China). The gonadal phase was observed in Zeiss microscopy. 


\subsection{RNA Extraction and Real-Time Quantitative PCR (RT-qPCR)}

Total RNAs was extracted from various tissues, including the intestines, coelom fluid, tube foot, ovary, and testis by using SV Total RNA Isolation System (Promaga Z3100). Embryos during different development stages, including egg, 4 cell, 16 cell, blastula, prism larva, 4 carpal and 8 carpals were collected to extract total RNAs $(n>50)$. Moreover, the gonads of early ontogeny were surgically removed under Zeiss microscopy to extract total RNAs. Total RNAs $(1 \mu \mathrm{g})$ of ovary and testis were used to establish cDNA library by using the SMARTer ${ }^{\mathrm{TM}}$ RACE cDNA Amplification Kit (Clontech 634923) according to the manufacture's protocols. Besides, $1 \mu \mathrm{g}$ of total RNAs were used to synthesize the first-strand cDNAs based on the protocols of GoScriptTMReverse Transcription System (Promega A5000).

RT-qPCR experiments were performed in $20 \mu \mathrm{L}$ reactions containing $2 \mu \mathrm{L}$ of cDNA that had been diluted 5 times, $0.8 \mu \mathrm{L}$ of each $10 \mathrm{mM}$ primer, $10 \mu \mathrm{L}$ of Fast Start Essential DNA Green Master (Roche, Mannheim, Germany) and $6.4 \mu \mathrm{L}$ sterile water. The protocol was $95^{\circ} \mathrm{C}(10 \mathrm{~min})$ for heat denaturing, then, 40 cycles of $95^{\circ} \mathrm{C}(15 \mathrm{~s}), 60^{\circ} \mathrm{C}(1 \mathrm{~min})$. All primers used were designed by the software of Primer5 (Table S1). The efficiency of primers discovery through standard curve formulation reached $96 \%$. Ubiquitin was used as an internal control [41]. The target genes relative expression was calculated with the $2^{-\Delta \Delta C t}$ method. For statistical analysis, Tukey's test and Student's $t$-test were calculated with SPSS software after normal distribution and homogeneity of variance test (SPSS Inc.). A probability (P) of $<0.05$ was considered statistically significant.

\subsection{Sequence and Phylogenetic Analyses}

The full-length Mnnanos 2 cDNA was achieved by $5^{\prime}$ and $3^{\prime}$ rapid amplification of cDNA ends (RACE). The DNAMAN software was used to predict the deduced amino acid sequences. Multiple protein sequence alignment was performed by Clustal W. The phylogenetic tree was constructed with MEGA version 5.0 by bootstrap analysis using the maximum-likelihood method (1000 replicates) and human NANOS2 was used as the outgroup sequences.

\subsection{In Situ Hybridization}

Gonad samples were fixed in $4 \%$ PFA at $4{ }^{\circ} \mathrm{C}$ overnight. Then, embedded in OCT and sections $(10 \mu \mathrm{m})$ were cut with frozen microtomy. Primers used for amplifying antisense and sense RNA probe templates containing a T7 RNA polymerase promoter were designed by the software of Primer5 (Table S1). After PCR amplification and PCR product recovery, the recovered purified PCR products were used as the templates for probes. Subsequently, the riboprobes were synthesized by using digoxigenin (DIG) RNA labeling kit (Roche) according to the manufacturer's protocol. Section tissues in-situ hybridization was carried out according to the previously described [42]. Digital images were photographed using a (Lecia DM4B) microscope.

\section{6. dsRNA Synthesis and Injection}

The gene-specific dsRNA was designed by https://www.dkfz.de/signaling/e-rnai3/ and synthesized with MEGAscript RNAi Kit (Thermo Fisher, Vilnius, Lithuania) according to the protocol. A total of 24 $M$. nudus samples with a mean shell diameter of $48.3 \pm 2 \mathrm{~mm}$ were randomly assigned to the control group and the knockdown group. Subsequently, $50 \mu \mathrm{L}$ PBS and $50 \mu \mathrm{L}$ PBS containing $0.631 \mu \mathrm{g}$ nanos 2 dsRNA were injected into sea urchins of the control group and the knockdown group, respectively. On the $24 \mathrm{~h}$ and $72 \mathrm{~h}$ after injection, three male sea urchins and three female sea urchins from each group were removed randomly, and their gonads were sampled to analyze dynamic expression changes of the germ cell marker genes.

\subsection{Western Blot Analysis}

The gonads at the pre-gametogenesis and NP renewal stages were collected and digestion with 300 $\mu \mathrm{L}$ radio-immunoprecipitation assay lysis buffer (RIPA) containing $1 \%$ protease inhibitor cocktail (Roche). 
Extracts were then resolved by 4-12\% Sure PAGE (GenScript, Piscataway, NJ, USA), electroblotted onto Immobilon ${ }^{\circledR}$-P transfer membranes. Western blotting used primary anti-Nanos2 rabbit antibodies (1:100). This was followed by incubation with goat anti-rabbit $\operatorname{IgG}$ (1:2000). The detection of immunoreactivity was by using the Immobilon TM Western HRP Substrate Luminol Reagent.

\subsection{Immunofluorescence Localization}

Gonads were fixed overnight in $4 \%$ paraformaldehyde, rinsed, and balanced in $30 \%$ sugar. Samples were embedded in OCT and frozen in liquid nitrogen and stored at $-80{ }^{\circ} \mathrm{C}$ until use. Serial sections were $7-\mu \mathrm{m}$ thick on poly-L-lysine-coated glass slides. The tissue was rehydrated with PBS, then sealed with $5 \%$ non-fat powdered milk and $0.5 \%$ Triton for $1 \mathrm{~h}$. Subsequently, gonads were incubated overnight at $4{ }^{\circ} \mathrm{C}$ with the primary anti-Nanos2 antibody (1:50) followed by incubation with goat anti-rabbit IgG Alexa Fluor TM Plus 488 (1:200). Digital images were taken on (Lecia DM4B) microscopes.

Supplementary Materials: Supplementary materials can be found at http://www.mdpi.com/1422-0067/20/11/ 2705/s1.

Author Contributions: Funding acquisition, Z.-H.S. and Y.-Q.C.; investigation, X.H., J.W., B.-Z.L. and J.-L.W.; resources, W.-J.Z.; writing—original draft, J.Z.

Funding: This work was fund by the Central Public-interest Scientific Institution Basal Research \& Key Laboratory of Sustainable Development of Marine Fisheries, Ministry of Agriculture, P. R. China, CAFS (Grant nos. 2018HY-XKQ01) and the National Natural Science Foundation of China (Grant nos. 31802276).

Conflicts of Interest: The authors declare no conflict of interest. The founding sponsors had no role in the design of the study; in the collection, analyses, or interpretation of data; in the writing of the manuscript, and in the decision to publish the results.

\section{References}

1. Wang, C.; Lehmann, R. Nanos is the localized posterior determinant in Drosophila. J. Cell 1991, 66, 637-647. [CrossRef]

2. Gribouval, L.; Sourdaine, P.; Lareyre, J.J.; Bellaiche, J.; Le Gac, F.; Mazan, S.; Guiardiere, C.; Auvray, P.; Gautier, A. The nanos1 gene was duplicated in early Vertebrates and the two paralogs show different gonadal expression profiles in a shark. Sci. Rep. 2018, 8, 6942. [CrossRef]

3. Han, K.; Chen, S.; Cai, M.; Jiang, Y.; Zhang, Z.; Wang, Y. Nanos3 not nanos1 and nanos2 is a germ cell marker gene in large yellow croaker during embryogenesis. Comp. Biochem. Physiol. B Biochem. Mol. Biol. 2018, 218, 13-22. [CrossRef] [PubMed]

4. Li, M.Q.; Luo, A.L.; Zhao, P.W.; Li, T.T.; Geng, S.S.; Liang, X.W.; Xu, H.Y.; Lu, Y.Q.; Lu, S.S.; Yang, X.G.; et al. Nanos2 is a molecular marker of inchoate buffalo spermatogonia. Anim. Reprod. Sci. 2017, 186, 44-51. [CrossRef]

5. Sun, Z.-H.; Wang, Y.; Lu, W.-J.; Li, Z.; Liu, X.-C.; Li, S.-S.; Zhou, L.; Gui, J.-F. Divergent expression patterns and function implications of four nanos genes in a hermaphroditic fish, epinephelus coioides. Int. J. Mol. Sci. 2017, 18, 685. [CrossRef]

6. De Keuckelaere, E.; Hulpiau, P.; Saeys, Y.; Berx, G.; van Roy, F. Nanos genes and their role in development and beyond. Cell. Mol. Life Sci. 2018, 75, 1929-1946. [CrossRef]

7. Asaoka-Taguchi, M.; Yamada, M.; Nakamura, A.; Hanyu, K.; Kobayashi, S. Maternal Pumilio acts together with Nanos in germline development in Drosophila embryos. Nat. Cell Biol. 1999, 1, 431-437. [CrossRef] [PubMed]

8. Tsuda, M.; Sasaoka, Y.; Kiso, M.; Abe, K.; Haraguchi, S.; Kobayashi, S.; Saga, Y. Conserved Role of nanos Proteins in Germ Cell Development. Science 2003, 301, 1239-1241. [CrossRef]

9. Beer, R.L.; Draper, B.W. Nanos3 maintains germline stem cells and expression of the conserved germline stem cell gene Nanos2 in the zebrafish ovary. Dev. Biol. 2013, 374, 308-318. [CrossRef]

10. Yu, M.; Mu, H.; Niu, Z.; Chu, Z.; Zhu, H.; Hua, J. miR-34c enhances mouse spermatogonial stem cells differentiation by targeting Nanos2. J. Cell. Biochem. 2013, 115, 232-242. [CrossRef] 
11. Zhou, Z.; Shirakawa, T.; Ohbo, K.; Sada, A.; Wu, Q.; Hasegawa, K.; Saba, R.; Saga, Y. RNA Binding Protein Nanos2 Organizes Post-transcriptional Buffering System to Retain Primitive State of Mouse Spermatogonial Stem. J. Cells Dev. Cell 2015, 34, 96-107. [CrossRef]

12. Zhang, W.; Bi, Y.; Wang, Y.; Li, D.; He, N.; Wang, M.; Jin, J.; Zuo, Q.; Zhang, Y.; Li, B. Nanos2 promotes differentiation of chicken (Gallus gallus) embryonic stem cells to male germ cells. J. Cell. Biochem. 2018, 119, 4435-4446. [CrossRef]

13. Bellaiche, J.; Lareyre, J.J.; Cauty, C.; Yano, A.; Allemand, I.; Le Gac, F. Spermatogonial stem cell quest: nanos2, marker of a subpopulation of undifferentiated A spermatogonia in trout testis. Biol. Reprod. 2014, 90, 79. [CrossRef]

14. Fresques, T.; Zazueta-Novoa, V.; Reich, A.; Wessel, G.M. Selective accumulation of germ-line associated gene products in early development of the sea star and distinct differences from germ-line development in the sea urchin. Dev. Dyn. 2014, 243, 568-587. [CrossRef] [PubMed]

15. Juliano, C.E.; Yajima, M.; Wessel, G.M. Nanos functions to maintain the fate of the small micromere lineage in the sea urchin embryo. Dev. Biol. 2010, 337, 220-232. [CrossRef]

16. Oulhen, N.; Wessel, G.M. Differential Nanos 2 protein stability results in selective germ cell accumulation in the sea urchin. Dev. Biol. 2016, 418, 146-156. [CrossRef] [PubMed]

17. Wei, Z.; Liu, X.; Feng, T.; Chang, Y. Novel and conserved micrornas in Dalian purple urchin (Strongylocentrotus nudus) identified by next generation sequencing. Int. J. Biol. Sci. 2011, 7, 180. [CrossRef]

18. Phillips, K.; Bremer, P.; Silcock, P.; Hamid, N.; Delahunty, C.; Barker, M.; Kissick, J. Effect of gender, diet and storage time on the physical properties and sensory quality of sea urchin (Evechinus chloroticus) gonads. Aquaculture 2009, 288, 205-215. [CrossRef]

19. Sun, Z.; Zhang, J.; Zhang, W.; Chang, Y. Gonadal transcriptomic analysis and identification of candidate sex-related genes in Mesocentrotus nudus. Gene 2019, 698, 72-81. [CrossRef] [PubMed]

20. Jia, Z.; Wang, Q.; Wu, K.; Wei, Z.; Zhou, Z.; Liu, X. De novo transcriptome sequencing and comparative analysis to discover genes involved in ovarian maturity in Strongylocentrotus nudus. Comp. Biochem. Physiol. Part D Genom. Proteom. 2017, 23, 27-38. [CrossRef] [PubMed]

21. Tian, Y.; Jiang, Y.; Shang, Y.; Zhang, Y.; Geng, C.; Wang, Q.; Chang, Y.Q. Establishment of lysozyme gene RNA interference systemand its involvement in salinity tolerance in sea cucumber (Apostichopus japonicus). Fish Shellfish Immunol. 2017, 65, 71-79. [CrossRef]

22. Yang, D.; Zhang, Z.; Liang, S.; Yang, Q.; Wang, Y.; Qin, Z. A novel role of Kruppel-like factor 4 in Zhikong scallop Chlamys farreri during spermatogenesis. PLoS ONE 2017, 12, e0180351. [CrossRef]

23. Yu, Y.; Ma, W.; Zeng, Q.; Qian, Y.; Yang, J.; Yang, W. Molecular Cloning and Sexually Dimorphic Expression of Two Dmrt Genes in the Giant Freshwater Prawn, Macrobrachium rosenbergii. Agric. Res. 2014, 3, $181-191$. [CrossRef]

24. Walker, C.W.; Tatsuya, U.; Michael, P.L. Gametogenesis and reproduction of sea urchins. Dev. Aquac. Fish. Sci. 2007, 37, 11-33.

25. Walker, R.A. Quantification of immunohistochemistry-issues concerning methods, utility and semiquantitative assessment. Histopathology 2006, 49, 406-410. [CrossRef] [PubMed]

26. Dwarakanath, M.; Lim, M.; Xu, H.; Hong, Y. Differential expression of boule and dazl in adult germ cells of the Asian seabass. Gene 2014, 549, 237-242. [CrossRef] [PubMed]

27. Yang, Y.; Wang, Y.; Li, Z.; Zhou, L.; Gui, J. Sequential, Divergent, and Cooperative Requirements of Foxl2a and Foxl2b in Ovary Development and Maintenance of Zebrafish. Genetics 2017, 205, 1551-1572. [CrossRef] [PubMed]

28. Nakamura, S.; Kobayashi, K.; Imura, T.; Higashijima, S.; Tanaka, M. Identification of Germline Stem Cells in the Ovary of the Teleost Medaka. Science 2010, 328, 1561-1563. [CrossRef]

29. Saba, R.; Kato, Y.; Saga, Y. Nanos2 promotes male germ cell development independent of meiosis suppression. Dev. Biol. 2014, 385, 32-40. [CrossRef]

30. Seydoux, K. Nos-1 and Nos-2, two genes related to Drosophila nanos, regulate primordial germ cell development and survival in Caenorhabditis elegans. Development 1999, 126, 4861-4871.

31. D'Agostino, I.; Merritt, C.; Chen, P.L.; Seydoux, G.; Subramaniam, K. Translational repression restricts expression of the C. elegans Nanos homolog NOS-2 to the embryonic germline. Dev. Biol. 2006, 292, $244-252$.

32. Saga, Y. Function of Nanos2 in the male germ cell lineage in mice. Cell. Mol. Life Sci. 2010, 67, 3815-3822. [CrossRef] [PubMed] 
33. Oulhen, N.; Yoshida, T.; Yajima, M.; Song, J.L.; Sakuma, T.; Sakamoto, N.; Yamamoto, T.; Wessel, G.M. The 3' UTR of nanos2 directs enrichment in the germ cell lineage of the sea urchin. Dev. Biol. 2013, 377, $275-283$. [CrossRef] [PubMed]

34. Lin, C.Y.; Su, Y.H. Genome editing in sea urchin embryos by using a CRISPR/Cas9 system. Dev. Biol. 2016, 409, 420-428. [CrossRef]

35. Peng, J.; Xie, J.; Zhou, L.; Hong, Y.; Gui, J. Evolutionary conservation of Dazl genomic organization and its continuous and dynamic distribution throughout germline development in gynogenetic gibel carp. J. Exp. Zool. B Mol. Dev. Evol. 2019, 312, 855-871.

36. Teaniniuraitemoana, V.; Huvet, A.; Levy, P.; Klopp, C.; Lhuillier, E.; Gaertner-Mazouni, N.; Gueguen, Y.; Le Moullac, G. Gonad transcriptome analysis of pearl oyster Pinctada margaritifera: Identification of potential sex differentiation and sex determining genes. BMC Genomics 2014, 15, 491. [CrossRef] [PubMed]

37. Meng, X.; Liu, P.; Jia, F.; Li, J.; Gao, B. De novo Transcriptome Analysis of Portunus trituberculatus Ovary and Testis by RNA-Seq: Identification of Genes Involved in Gonadal Development. PLoS ONE 2015, 10, e0128659. [CrossRef]

38. Schmidt, D.; Ovitt, C.E.; Anlag, K.; Fehsenfeld, S.; Gredsted, L.; Treier, A.C.; Treier, M. The murine winged-helixtranscription factor Foxl2 is required for granulosa celldifferentiation and ovary maintenance. Development 2004, 131, 933-942. [CrossRef]

39. Li, Q.; Xie, J.; He, L.; Wang, Y.; Yang, H.; Duan, Z.; Wang, Q. FOXL2 down-regulates vitellogenin expression at mature stage in Eriocheir sinensis. Biosci. Rep. 2015, 35, e0278. [CrossRef]

40. Govoroun, M.S.; Pannetier, M.; Pailhoux, E.; Cocquet, J.; Brillard, J.P.; Couty, I.; Batellier, F.; Cotinot, C. Isolation of chicken homolog of the FOXL2 gene and comparisonof its expression patterns with those of aromatase during ovarian development. Dev. Dyn. 2004, 231, 859-870. [CrossRef]

41. Konstantin, V.; Yakovlev, N.R.; Battulin, O.L.; Serov, N.A.; Odintsova, N.A. Isolation of oogonia from ovaries of the sea urchin Strongylocentrotus Nudus. Cell Tissue Res. 2010, 342, 479-490.

42. Wang, Y.; Sun, Z.; Zhou, L.; Li, Z.; Gui, J. Grouper Tsh $\beta$ promoter-driven transgenic zebrafish marks proximal kidney tubule development. PLoS ONE 2014, 9, e97806. [CrossRef] [PubMed]

(C) 2019 by the authors. Licensee MDPI, Basel, Switzerland. This article is an open access article distributed under the terms and conditions of the Creative Commons Attribution (CC BY) license (http://creativecommons.org/licenses/by/4.0/). 